\title{
Randomised trial of early tapping in neonatal posthaemorrhagic ventricular dilatation: results at 30 months
}

\author{
Ventriculomegaly Trial Group
}

\begin{abstract}
One hundred and fifty seven infants with progressive ventricular dilatation after intraventricular haemorrhage were randomised to either early repeated cerebrospinal fluid tapping or conservative management. Thirty two $(20 \%)$ infants died and $13(8 \%)$ were lost to follow up. One hundred and twelve children $(90 \%$ of survivors) were examined at $\mathbf{3 0}$ months by a single experienced examiner. Overall, 54 $(48 \%)$ scored less than 70 on the Griffiths developmental scales, $101(90 \%)$ had neuromotor impairment, and $85(76 \%)$ had marked disability; $63(56 \%)$ had multiple impairments. Vision was severely affected in $10(9 \%)$ and $30(27 \%)$ had a field defect. Six per cent (seven children) had sensorineural hearing loss and $16(14 \%)$ were taking regular anticonvulsant drugs. Although early cerebrospinal fluid tapping reduced the rate of ventricular and head expansion, there was no statistically significant difference (at the $5 \%$ level) between the treatment groups in the prevalence of neuromotor impairments, non-neuromotor impairments, nor multiple impairments at $\mathbf{3 0}$ months. These findings were consistent regardless of the presence or absence of a parenchymal cerebral lesion at entry to the trial. In the light of these findings and the $7 \%$ risk of cerebrospinal fluid infection associated with repeated tapping, this form of early intervention cannot be recommended.
\end{abstract}

(Arch Dis Child 1994; 70: F129-F136)

Progressive ventricular dilatation leading to hydrocephalus is the most serious direct complication of intraventricular haemorrhage in preterm infants. The survivors have probably the worst prognosis of any defined group of newborn infants. In south western Sweden, where epidemiological surveillance of neurological disabilities in young children has been maintained for over 20 years, concern has been expressed about the emergence during the 1980 s of a population of preterm infants with posthaemorrhagic hydrocephalus and multiple severe disabilities. ${ }^{1}$ Among preterm infants born during 1983-6 and surviving this complication, $78 \%$ had cerebral palsy, $72 \%$ had a development or intelligence quotient of less than 70 , and $56 \%$ had epilepsy. ${ }^{1}$ These workers even suggested that the disorder could be used as an index of trends in neonatal neurological morbidity in large populations as the diagnosis was considerably more rapid and certain than cerebral palsy. Shankaran et al ${ }^{2}$ followed up prospectively a group of 33 infants with posthaemorrhagic ventricular dilatation (PHVD) to a mean age of 50 months. Not all of the infants required shunt operations but $58 \%$ had delayed motor development and 52\% had delayed mental development.

The mechanism of PHVD is thought to include the initial obstruction of cerebrospinal fluid pathways and the arachnoid villi by multiple small blood clots, and later basal cistern arachnoiditis leading to permanent hydrocephalus. ${ }^{3}$ Progressive PHVD is usually accompanied by increased cerebrospinal fluid pressure, though some immature brains and skulls can expand at pressures only slightly over the upper limit of normal $(6 \mathrm{~mm} \mathrm{Hg}, 0.8$ $\mathrm{kPa}){ }^{4}$ Animal models of hydrocephalus have shown that ventricular dilatation driven by cerebrospinal fluid pressure produces flattening and destruction of the ependymal lining, with oedema and destruction of the periventricular white matter. ${ }^{56}$ There is evidence from neuropathological studies that a similar process occurs in the developing brain of the newborn infant. ${ }^{7}$ Such periventricular damage would be likely to lead to motor deficits but mental and sensory functions of the brain might also be damaged and epileptic foci initiated if the effects of oedema and pressure were more widespread in the small immature brain.

Treatment of infants with PHVD has been frustrating. Ventriculoperitoneal shunt insertion is usually not feasible for many weeks because of the high blood and protein content of the cerebrospinal fluid, and the extremely small size and poor pulmonary status of many of the infants as well as the high risk of infection. ${ }^{2}$ Drugs may be used to reduce the production of cerebrospinal fluid but no randomised trial has shown clinical benefit. The most widely used drug, acetazolamide, can worsen carbon dioxide retention in infants with chronic lung disease ${ }^{9}$ and has a small risk of aplastic anaemia. ${ }^{10}$ Repeated removal of cerebrospinal fluid by tapping to lower cerebrospinal fluid pressure and to slow down ventricular dilatation has some logic as a treatment. Observational studies have suggested that serial tapping might improve neurodevelopmental outcome. ${ }^{11-14}$ Two small randomised trials suggested that repeated spinal tapping did not reduce the need for a later operation to insert a shunt. ${ }^{15} 16$ In a third trial, Dykes et al compared early repeated lumbar 
puncture with observation in a group of infants with PHVD. ${ }^{17}$ Of 29 who survived, examination at 3-6 years showed there was a lower proportion of children with major disability in the group treated with early lumbar punctures, but the difference was not statistically significant.

Because of the uncertainties about the value of early cerebrospinal fluid tapping, we mounted a large multicentre randomised trial in which early management of PHVD by repeated cerebrospinal fluid taps was compared with conservative management. The principal outcome measure was neurodevelopmental status in the survivors. The results at the age of 12 months (corrected age) have previously been reported. ${ }^{18}$ Of 127 children surviving at the time, 121 were examined and $103(85 \%)$ of these were found to have had abnormal neuromotor signs with $88(73 \%)$ having disabilities. There was no detectable benefit of early treatment for children who did not have a parenchymal lesion at entry to the trial. Nearly all those with parenchymal lesions had neuromotor impairment, but early treatment was associated with a reduction in other impairments, which was marginally statistically significant $(p=0 \cdot 05)$. Other important findings were that cerebrospinal fluid infection occurred in $7 \%$ of infants with repeated taps, and $63 \%$ of survivors in the two groups ultimately had an operation to insert a shunt.

We now present the results of follow up at the age of 30 months post-term. Examination at this age was important: (a) because disorders of speech and language development cannot be evaluated at 12 months - the assessment of speech and language at 30 months gives an indication of cognitive function; (b) because, though the underlying neuromotor impairments may not change, the functional status may evolve significantly after 12 months; (c) because a longer term view of general morbidity in the child and family can be obtained at 30 months than at 12 months in this, the largest group of children hitherto studied with PHVD; and (d) to determine whether the previous statistically borderline difference in the group with parenchymal lesions was confirmed or not.

\section{Patients and methods}

The full details of the patients and methods have previously been described ${ }^{18}$ and only the essential details will be presented here. Infants with PHVD were recruited from 15 neonatal intensive care units in England, Ireland, and Switzerland. The protocol was agreed by neonatologists in each centre and then approved by each local research ethics committee. Written or oral parental consent was given for each infant.

\section{ELIGIBILITY}

Infants were eligible if all the following criteria were met: (a) intraventricular haemorrhage shown by ultrasound scan; (b) ventricular width less than the 97 th centile ${ }^{19}$ on the first scan or the first scan showed a clot distending the ventricle - ventricular width was measured from the midline to the lateral border of the lateral ventricle at the level of the intraventricular foramina on a coronal scan; (c) serial measurements of ventricular width showing a progressive increase; and (d) ventricular width of $4 \mathrm{~mm}$ or more above the $97 \mathrm{th}$ centile. ${ }^{19}$ In the case of asymmetrical dilatation, the smaller of the two ventricles had to meet the criteria.

\section{TREATMENT ALLOCATION}

After eligibility had been confirmed, infants were entered into the trial by telephoning the Clinical Trial Service Unit in Oxford. The clinician first gave details for identification and was then told the random allocation to either early treatment with taps or conservative management. Participating neonatologists were asked to record the presence or absence of parenchymal cerebral lesions on each side at entry to the trial. 'Parenchymal lesion' included parenchymal 'extension' of intraventricular haemorrhage and periventricular leukomalacia. Non-communicating hydrocephalus was defined as the inability to obtain more than 2 $\mathrm{ml}$ cerebrospinal fluid by lumbar puncture.

\section{TREATMENT SCHEDULES}

Early treatment

The object of early treatment was to prevent further ventricular dilatation. A lumbar puncture was carried out and cerebrospinal fluid allowed to drain until a maximum of $2 \%$ of the body weight had been drained. Lumbar punctures were repeated as often as necessary if ventricular width increased by $2 \mathrm{~mm}$ or more above the measurement before the first tap. If lumbar puncture yielded no more than $2 \mathrm{ml}$ cerebrospinal fluid, ventricular puncture could be performed and repeated as necessary. If repeated taps were necessary for more than four weeks, and head enlargement continued, permanent shunting was considered, but the decision to insert a shunt also depended on the general condition and weight of the infant, and the cerebrospinal fluid protein concentration.

\section{Conservative management}

Ventricular size on ultrasound did not dictate management. The infants were observed without intervention. The criteria for removal of cerebrospinal fluid were (a) excessive head enlargement - that is, double the normal head circumference velocity after entry into the trial for at least two weeks ${ }^{20}$; or (b) symptomatic increased intracranial pressure with a measured cerebrospinal fluid pressure greater than 1.6 $\mathrm{kPa}(12 \mathrm{~mm} \mathrm{Hg})$. If a bulging fontanelle and neurological abnormality suggested increased intracranial pressure, a lumbar puncture or ventricular puncture could be carried out.

The criteria for permanent shunting were the same in the two treatment groups - that is, failure to control head size with no contraindication to shunting, such as severe cardiopulmonary disease, infection, or high cerebrospinal fluid protein. 
STATISTICAL ANALYSIS

Before starting the trial it was estimated that 60 surviving infants in each treatment group would give an $80 \%$ chance of detecting a statistically significant $(p<0.05)$ reduction in impairments from 50 to $25 \%$. We expected PHVD to occur in $3-4 \%$ of infants under $1500 \mathrm{~g}$ (very low birth weight) and to be associated with a mortality of $20 \%$. The 15 collaborating neonatal units were expected to admit about 1500 very low birthweight infants each year, so a recruitment period of three years was planned (January 1984-January 1987). Analyses have been based on the groups as allocated, regardless of subsequent management. There was no interim analysis. The $5 \%$ level of statistical significance is used. Differences are presented with $95 \%$ confidence intervals where appropriate.

PRIMARY HYPOTHESIS

The underlying assumption was that the damage due to the original ventricular dilatation was likely to affect the neuromotor area initially. The aim of the intervention was to prevent extension by compression to other areas of the brain such as those responsible for vision, hearing, and cognitive function. An impairment in vision, hearing, or cognitive function, or impairment in the form of seizure activity at 30 months might therefore imply that this extension had occurred. Comparison of the proportion of children with non-neuromotor impairment in the two treatment groups would test this aetiological hypothesis. Stratification by the presence or absence of a parenchymal lesion recognised at trial entry was carried out to see if the effect of intervention differed according to this prognostic factor.

FOLLOW UP ASSESSMENT OF SURVIVORS AT 30 MONTHS' CORRECTED AGE

Surviving children were seen in their own homes at about 30 months after the expected date of delivery. All those examined except one were seen by a single developmental paediatrician, Dr L Mutch, who was unaware of their original trial allocation. One British child was seen by his local paediatrician. The assessment consisted of an interval history, standardised neurological examination as described by Amiel-Tison and Stewart, ${ }^{21}$ the Griffiths developmental scales, ${ }^{22}$ Reynell language scales, ${ }^{23}$ the Vineland adaptive behaviour scales, ${ }^{24}$ and a parental questionnaire incorporating the Rutter parents' questionnaire modified by Watt et al. ${ }^{25}$ Height, weight, and head circumference were measured and plotted on centile charts. ${ }^{26}$ At the time of the study assessment, near visual acuity was measured by a range of objects of diameter 2-25 mm presented at distances of 11-36 $\mathrm{cm} .{ }^{27}$ Distant visual acuity was measured by presenting standard pictures of familiar objects at distances of 1-3 m. Hearing levels necessary for speech development were assessed by responsiveness to a whispered voice and a high tone rattle.
The need for hospital admission and the use of services such as physiotherapy, speech and occupational therapy, orthoptic treatment, and home teaching were recorded.

\section{Definition of outcomes}

The neurological status of the children at 30 months was defined in terms of the presence or absence of neuromotor impairments, other neurological impairments, neurosensory and neurodevelopmental impairments, and their effects on the child's functional abilities. For the purposes of the trial, the primary analysis focused on the extent of neurological damage as revealed by standardised assessments of these areas.

Neuromotor impairment. This was defined as the presence of abnormalities of tone, reflexes, or posture identified by structured neurological examination ${ }^{21}$ and judged according to age dependent standards. Neuromotor impairments were further categorised by whether there was functional loss, or not.

Other neurological impairment with disability. This was deemed to be present if (a) the child had seizures and was receiving regular anticonvulsant drugs or (b) the child had difficulty with swallowing liquids or solids. Lesser degrees of neurological impairment such as neurobehavioural problems without functional loss could not be identified reliably because of the young age of the children.

Neurosensory impairment. At the age of 30 months, the value of both pure tone audiometry and full vision assessment are limited by the ability of the child to participate in the assessment. In the course of the clinical assessment it was possible to form only a crude clinical judgment of the child's ability to hear sufficiently to allow the development of language. Only auditory or visual neurosensory impairments causing functional loss could be identified from the clinical methods available for testing these young children aged 30 months.

Children who had been identified by 30 months as having a hearing loss of sufficient severity to require a hearing aid were assumed to have sensorineural hearing loss and were classified as having a neurosensory impairment with functional loss (disability). It was not possible to distinguish on clinical grounds either unilateral sensorineural loss or high tone losses which had not been considered severe enough to warrant aiding, from conductive losses due to secretory otitis media.

Children who were blind or able to see light only, or whose near vision was such that they could not see an object of less than $25 \mathrm{~mm}$ in diameter, ${ }^{27}$ or who had nystagmus, or who had a visual field defect, were considered to have a neurosensory (visual) impairment with functional loss. Mild defects of near vision (the inability to see objects of $15 \mathrm{~mm}$ or less) were assumed to be due to refractive errors. These deficits and squints were not classified as neurosensory impairments.

Neurodevelopmental impairment. This was assessed and categorised in two ways: (a) 


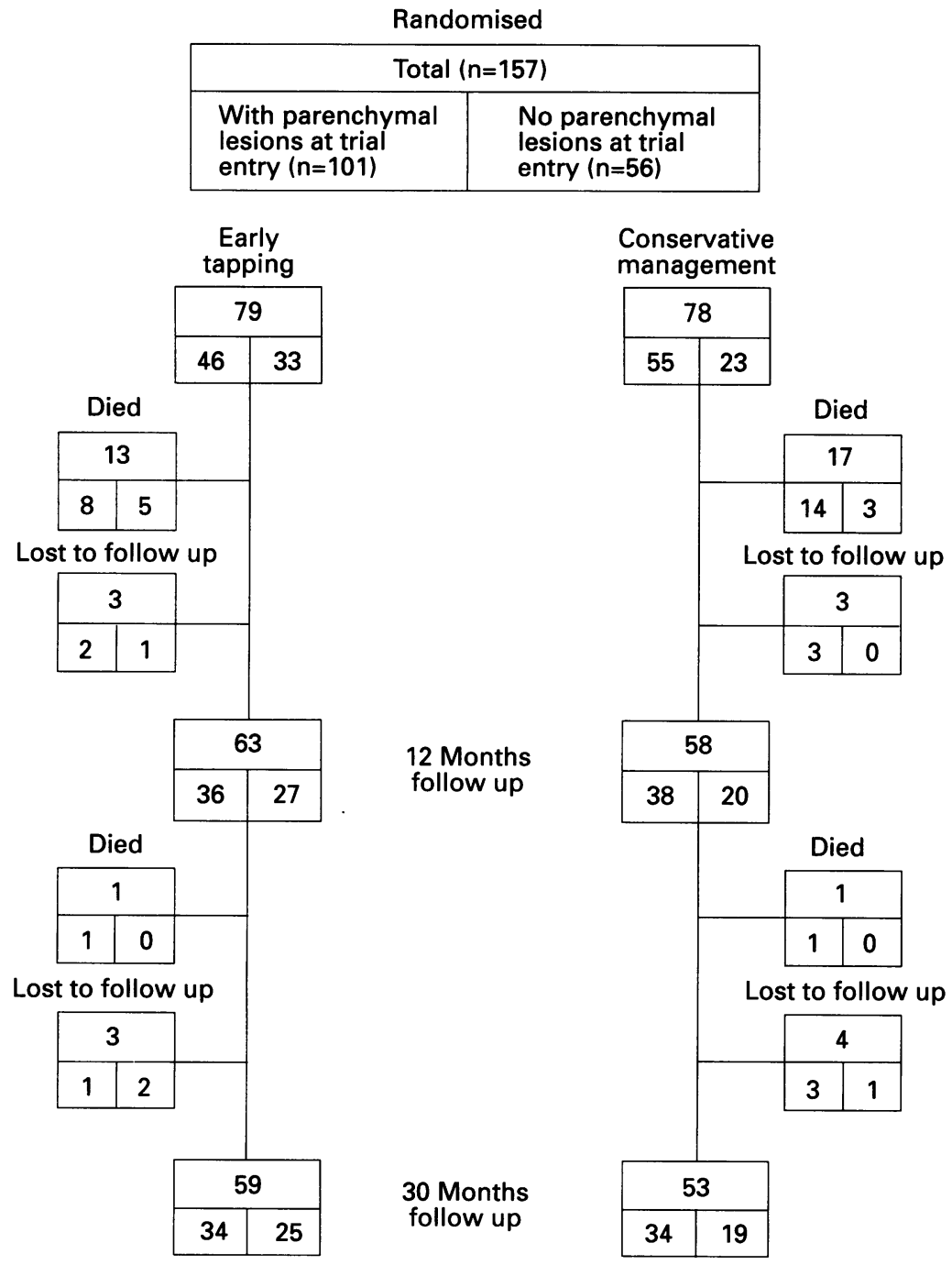

Follow up of infants entered into the trial.

Table 1 Characteristics of treatment groups at trial entry. Values are mean (SD) unless otherwise indicated

\begin{tabular}{|c|c|c|c|c|}
\hline & \multicolumn{2}{|l|}{ All randomised } & \multicolumn{2}{|c|}{ Survivors seen at 30 months } \\
\hline & $\begin{array}{l}\text { Early } \\
\text { tapping } \\
(n=79)\end{array}$ & $\begin{array}{l}\text { Conservative } \\
\text { management } \\
(n=78)\end{array}$ & $\begin{array}{l}\text { Early } \\
\text { tapping } \\
(n=59)\end{array}$ & $\begin{array}{l}\text { Conservative } \\
\text { management } \\
(n=53)\end{array}$ \\
\hline $\begin{array}{l}\text { No }(\%) \text { of boys } \\
\text { Birth weight (g) } \\
\text { Gestational age (weeks) } \\
\text { Age at trial entry (days) } \\
\text { Total }(\%) \text { with parenchymal bra }\end{array}$ & $\begin{array}{c}57(72) \\
1220(440) \\
28 \cdot 3(2 \cdot 8) \\
19 \cdot 1(11 \cdot 2)\end{array}$ & $\begin{array}{c}49(63) \\
1245(436) \\
28 \cdot 4(2 \cdot 9) \\
16 \cdot 0(7 \cdot 4)\end{array}$ & $\begin{array}{c}42(71) \\
1224(446) \\
28 \cdot 2(2 \cdot 7) \\
20 \cdot 1(11 \cdot 3)\end{array}$ & $\begin{array}{c}32(60) \\
1314(493) \\
28 \cdot 7(3 \cdot 1) \\
16 \cdot 3(7 \cdot 6)\end{array}$ \\
\hline $\begin{array}{l}\text { lesions } \\
\text { No (\%) with bilateral lesions } \\
\text { No }(\%) \text { with ventriculospinal }\end{array}$ & $\begin{array}{l}46^{\star}(58) \\
12(15)\end{array}$ & $\begin{array}{l}55(71) \\
17(22)\end{array}$ & $\begin{array}{r}34(58) \\
9(15)\end{array}$ & $\begin{array}{r}34(64) \\
9(17)\end{array}$ \\
\hline $\begin{array}{l}\text { communication at entry } \\
\text { Cerebrospinal fluid pressure }\end{array}$ & $61(77)$ & $65(83)$ & $47(80)$ & $45(85)$ \\
\hline $\begin{array}{l}\text { (mm Hg) } \\
\text { Ventricular width (mm) }\end{array}$ & $\begin{array}{r}9 \cdot 2(4 \cdot 7) \\
17 \cdot 9(2 \cdot 0)\end{array}$ & $\begin{array}{r}8 \cdot 9(5 \cdot 9) \\
17 \cdot 3(2 \cdot 1)\end{array}$ & $\begin{array}{r}9 \cdot 0(4 \cdot 8) \\
17 \cdot 9(2 \cdot 0)\end{array}$ & $\begin{array}{r}8 \cdot 3(4 \cdot 3) \\
17 \cdot 4(2 \cdot 1)\end{array}$ \\
\hline
\end{tabular}

*This is one fewer than originally thought as investigations for the $\mathbf{3 0}$ month follow up detected three errors: two infants had been incorrectly classified as having a parenchymal lesion at trial entry, and one infant originally classified as 'not known' was subsequently discovered to have had such a lesion before trial entry. All three of these infants were in the group allocated to early tapping.

overall development - a Griffiths score of less than 70 (corrected for gestational age) was regarded as abnormal and to indicate a disabling impairment; (b) language impairment a standard score on the comprehension scale of the revised Reynell language scales less than -1.5 (an age level equivalent to 20-21 months) was considered to indicate impaired language development and to be causing disability.

\section{OVERALL STATUS}

To provide an overall picture of the individual child's neurological status and to judge whether extension of the initial periventricular damage had occurred, these impairments were grouped as shown in the following. For the purposes of this analysis, language development (indicated by the Reynell comprehension scale), rather than overall development (Griffiths score), was considered as it was believed to be a more specific indicator of cognitive skills. (1) Normal: no neuromotor, neurosensory, nor other neurological impairment, with Reynell comprehension scale standard score better than $-1 \cdot 5$. (2) Neuromotor impairment alone without functional loss. (3) Neuromotor impairment with functional loss (disability) but no impairment in other domains. (4) No neuromotor impairment but impairment with functional loss (disability) in one other domain - for example, neurosensory, other neurological or neurodevelopmental domains. (5) Multiple system impairment in two or more domains - for example, neuromotor impairment and impairment of neurological, neurosensory, or neurodevelopmental domains with functional loss.

\section{Results}

The figure shows the derivation of the groups compared at 30 months. One hundred and fifty seven infants were randomised, 79 to early tapping and 78 to conservative management. Thirty infants died before 12 months' corrected age. Information was not available about six of the survivors, three because they had left the country, two from Switzerland, and one at the paediatrician's request, leaving 121 who were examined at 12 months' corrected age. Two more infants subsequently died before 30 months' corrected age and information was not available from a further seven survivors (two from Switzerland, two where parents refused assessment, and three who had moved abroad). Thus 112 children, 59 randomised to early tapping and 53 randomised to conservative management $(90 \%$ of survivors) were examined at 30 months' corrected age. Table 1 shows the characteristics of those randomised and the survivors seen at 30 months. They were mostly very low birth weight, very preterm infants with no statistically significant differences in the distribution of the characteristics between those randomised and those who were examined, and between those receiving early drainage and those receiving conservative management. Cerebrospinal fluid pressure was measured in most of the infants and the mean pressure was about three times the normal mean. ${ }^{7}$

Table 2 gives the morbidity between discharge and 30 months. In the two trial groups, four fifths had been readmitted to hospital and one third had required a shunt revision.

Table 3 shows the scores on the (corrected) Griffiths developmental scales at 30 months. On the locomotor quotient, 62 (55\%) scored below $70,45(40 \%)$ below 70 on the social 
Table 2 Morbidity between discharge from neonatal unit and 30 months' follow up. Values are number (\%) of subjects

\begin{tabular}{lll}
\hline & $\begin{array}{l}\text { Early } \\
\text { tapping } \\
(n=59)\end{array}$ & $\begin{array}{l}\text { Conservative } \\
\text { management } \\
(n=53)\end{array}$ \\
\hline Hospital readmission & $45(76)$ & $44(83)$ \\
Once & $11(19)$ & $15(28)$ \\
Twice & $15(25)$ & $13(25)$ \\
Three or more & $19(32)$ & $16(30)$ \\
Admission for revision of shunt & $18(31)$ & $18(34)$ \\
Infections & $22(37)$ & $23(43)$ \\
Ear & $38(64)$ & $26(49)$ \\
Chest & $22(37)$ & $21(40)$ \\
Other & & \\
\hline
\end{tabular}

Table 3 Griffiths development scales at 30 months (corrected for gestational age). Values are number (\%) of subjects

\begin{tabular}{|c|c|c|}
\hline & $\begin{array}{l}\text { Early } \\
\text { tapping } \\
(n=59)\end{array}$ & $\begin{array}{l}\text { Conservative } \\
\text { management } \\
(n=53)\end{array}$ \\
\hline \multicolumn{3}{|l|}{ Locomotor quotient } \\
\hline Not measurable & $5(8)$ & $8(15)$ \\
\hline$<50$ & $17(29)$ & $10(19)$ \\
\hline $50-69$ & $10(17)$ & $12(23)$ \\
\hline $70-84$ & $16(27)$ & $12(23)$ \\
\hline $85-114$ & $11(19)$ & $10(19)$ \\
\hline $115+$ & & $1(2)$ \\
\hline \multicolumn{3}{|l|}{ Social scale quotient } \\
\hline Not measurable & $5(8)$ & $8(15)$ \\
\hline$<50$ & $4(7)$ & $6(11)$ \\
\hline $50-69$ & $12(20)$ & $10(19)$ \\
\hline 70-84 & $12(20)$ & $11(21)$ \\
\hline $85-114$ & $22(37)$ & $14(26)$ \\
\hline $115+$ & $4(7)$ & $4(8)$ \\
\hline \multicolumn{3}{|c|}{ Hearing and speech quotient } \\
\hline Not measurable & $5(8)$ & $8(15)$ \\
\hline$<50$ & $7(12)$ & $8(15)$ \\
\hline $50-69$ & $12(20)$ & $5(9)$ \\
\hline $70-84$ & $11(19)$ & $13(25)$ \\
\hline $85-114$ & $16(27)$ & $15(28)$ \\
\hline $115+$ & $8(14)$ & $4(8)$ \\
\hline \multicolumn{3}{|c|}{ Eye-hand coordination } \\
\hline Not measurable & $5(8)$ & $8(15)$ \\
\hline$<50$ & $6(10)$ & $7(13)$ \\
\hline $50-69$ & $19(32)$ & $13(25)$ \\
\hline $70-84$ & $14(24)$ & $10(19)$ \\
\hline $85-114$ & $15(25)$ & $14(26)$ \\
\hline $115+$ & 0 & $1(2)$ \\
\hline \multicolumn{3}{|c|}{ Performance quotient } \\
\hline Not measurable & $5(8)$ & $8(15)$ \\
\hline$<50$ & $6(10)$ & $7(13)$ \\
\hline $50-69$ & $13(22)$ & $9(17)$ \\
\hline $70-84$ & $16(27)$ & $15(28)$ \\
\hline $85-114$ & $15(25)$ & $7(13)$ \\
\hline $115+$ & $4(7)$ & 7 (13) \\
\hline \multicolumn{3}{|l|}{ Overall quotient } \\
\hline Not measurable & $5(8)$ & $8(15)$ \\
\hline$<50$ & $6(10)$ & $8(15)$ \\
\hline $50-69$ & $18(31)$ & $9(17)$ \\
\hline $70-84$ & $10(17)$ & $11(21)$ \\
\hline $85-114$ & $19(32)$ & $15(28)$ \\
\hline $115+$ & $1(2)$ & $2(4)$ \\
\hline
\end{tabular}

Table 4 Neuromotor findings at 30 months. Values are number (\%) of subjects

\begin{tabular}{|c|c|c|c|c|}
\hline & \multicolumn{2}{|c|}{$\begin{array}{l}\text { Early tapping } \\
(n=59)\end{array}$} & \multicolumn{2}{|c|}{$\begin{array}{l}\text { Conservative management } \\
(n=53)\end{array}$} \\
\hline & All & Functional loss & All & Functional loss \\
\hline \multicolumn{5}{|l|}{ Hypertonia affecting } \\
\hline Four limbs & $8(14)$ & $8(14)$ & $8(15)$ & $8(15)$ \\
\hline Three limbs & $7(12)$ & $6(10)$ & 7 (13) & $6(11)$ \\
\hline Both legs & $24(41)$ & $7(12)$ & $22(42)$ & $5(9)$ \\
\hline Leg and arm same side & $4(7)$ & $2(3)$ & $2(4)$ & 0 \\
\hline One limb & $8(14)$ & $3(5)$ & $6(11)$ & 0 \\
\hline \multicolumn{5}{|l|}{ Axial tone } \\
\hline Global hypotonia & $3(5)$ & & $11(21)$ & \\
\hline Flexion/extension imbalance & $16(27)$ & & $11(21)$ & \\
\hline \multicolumn{5}{|l|}{ Asymmetry } \\
\hline Both pairs of limbs & $17(29)$ & & $19(36)$ & \\
\hline One pair of limbs & $18(31)$ & & $14(26)$ & \\
\hline \multicolumn{5}{|l|}{ Abnormal hands } \\
\hline Both & $5(9)$ & & $5(9)$ & \\
\hline One & $13(22)$ & & $11(21)$ & \\
\hline Abnormal postural reflexes & $20(34)$ & & $19(36)$ & \\
\hline No neuromotor abnormality & $5(9)$ & & $6(11)$ & \\
\hline
\end{tabular}

quotient, 45 (40\%) below 70 on the hearing and speech quotient, $58(52 \%)$ below 70 on the eye-hand coordination, and 48 (43\%) below 70 on the performance quotient. On the overall quotient, $54(48 \%)$ scored below 70 . There were no statistically significant differences between the two treatment groups at the $5 \%$ level.

Abnormalities of tone with functional loss were found in $40 \%$ of the children in the two treatment groups. Only $10 \%$ were normal on neuromotor examination (table 4). Seizures had occurred in $20(18 \%)$ infants and 16 (14\%) were taking regular anticonvulsant drugs at 30 months. A considerable number had significant problems with feeding and swallowing. Vision was severely affected in 10 $(9 \%)$ with a field defect in $30(27 \%)$. Squint was even more common, occurring in 44 $(39 \%)$ overall. Thirteen $(12 \%)$ of children had bilateral hearing impairment with seven $(6 \%)$ having sensorineural hearing loss. The two trial groups were similar in these respects (table 5).

Table 6 shows that, in the two treatment groups, the distribution of height is shifted downwards on the centile graph with $18 \%$ being below the 3 rd centile. The head circumference distribution shows $18 \%$ below the 3 rd centile, whereas $13 \%$ were above the 97 th centile.

Table 7 shows the proportion of children with single or multiple impairments. Only 10 (9\%) were without any impairment and 36 $(32 \%)$ had only neuromotor impairment. Sixty three $(56 \%)$ had multiple system impairment and all of these children had neuromotor impairment plus impairments in one or more other domains. There were three children who had visual field defects without any other impairment. Differences between the two treatment groups were not significant at the $5 \%$ level. This conclusion was not altered after stratification according to the presence or absence of a parenchymal cerebral lesion at entry. Table 7 shows that $20(45 \%)$ of those without a parenchymal lesion and $43(63 \%)$ of those with a parenchymal lesion had developed multiple impairments.

Table 8 compares the status of individual children as assessed at 30 months with their status at 12 months of age. Nine infants were

Table 5 Other neurological and neurosensory impairments. Values are number (\%) of subjects

\begin{tabular}{lcc}
\hline & $\begin{array}{l}\text { Early } \\
\text { tapping } \\
(n=59)\end{array}$ & $\begin{array}{l}\text { Conservative } \\
\text { management } \\
(n=53)\end{array}$ \\
\hline Seizures since discharge from & & \\
hospital & $9(15)$ & $11(21)$ \\
Regular anticonvulsant treatment & $6(10)$ & $10(19)$ \\
Problems swallowing & $7(12)$ & $8(15)$ \\
Solids & $3(5)$ & $3(6)$ \\
Liquids & $17(29)$ & $13(25)$ \\
Excessive dribbling & $6(10)$ & $8(15)$ \\
Cannot self feed & $44(75)$ & $32(60)$ \\
Near vision: ability to see objects $(m m$ in diameter) & $7(13)$ \\
2 & $7(12)$ & $7(13)$ \\
$3-4$ & $1(2)$ & 0 \\
15 & $3(5)$ & $1(2)$ \\
25 & 0 & $6(12)$ \\
50 & $4(7)$ & $10(19)$ \\
No vision or sees light only & $5(9)$ & $17(32)$ \\
Nystagmus & $27(46)$ & $14(26)$ \\
Squint (but sees objects) & $16(27)$ & $4(8)$ \\
Visual field defect & $3(5)$ & \\
Sensorineural hearing loss & & \\
\hline
\end{tabular}


Table 6 Growth at 30 months. Values are number (\%) of subjects unless otherwise indicated

\begin{tabular}{lcc}
\hline & $\begin{array}{l}\text { Early } \\
\text { tapping } \\
(n=59)\end{array}$ & $\begin{array}{l}\text { Conservative } \\
\text { management } \\
(n=53)\end{array}$ \\
\hline Mean (SEM) height (cm) & $86 \cdot 8(5 \cdot 0)$ & $87 \cdot 2(5 \cdot 2)$ \\
Height centile & $12(20)$ & $8(15)$ \\
$<3$ rd & $6(10)$ & $5(9)$ \\
3-10 & $33(56)$ & $33(62)$ \\
$10-90$ & $2(3)$ & $1(2)$ \\
$90-97$ & $1(2)$ & $1(2)$ \\
>97th & $5(8)$ & $5(10)$ \\
Not measured & $49 \cdot 0(2 \cdot 9)$ & $49 \cdot 1(3 \cdot 1)$ \\
Mean (SEM) head & $12(20)$ & $8(15)$ \\
circumference (cm) & $7(12)$ & $5(9)$ \\
Head circumference centile & $26(44)$ & $25(47)$ \\
<3rd & $6(10)$ & $7(13)$ \\
3-10 & $7(12)$ & $7(13)$ \\
10-90 & $1(2)$ & $1(2)$ \\
90-97 & & \\
>97th & & \\
Not measured & & \\
\hline
\end{tabular}

assessed at 12 months but not at 30 months. The two who died (one from each randomly allocated group) had parenchymal lesions at trial entry and multiple system involvement at 12 months. Four others also had multiple system involvement at 12 months and their parents either refused follow up at 30 months or their families had emigrated. The remaining three had a neuromotor impairment (two with disability) at 12 months (one of whose families had emigrated and two were from Switzerland).

Two thirds (76) of the 112 children assessed at both points in time had not changed status (according to the categorisations used) over this time period. Four children with neuromotor impairment at 12 months were assessed as normal at $\mathbf{3 0}$ months, and two children with multiple impairments at 12 months were assessed as having neuromotor impairment alone at 30 months. Nineteen (17\%) children were found at 30 months to have non-neuromotor impairments which had not been found at the 12 months' examination. Three of these 19 had visual impairment only. The remaining 16 all had neuromotor impairment and also either impaired language development (eight children) visual impairment (five children), language and visual impairment (one child),

Table 7 Overall outcome. Values are number (\%) of subjects

\begin{tabular}{lcc}
\hline & $\begin{array}{c}\text { Early } \\
\text { tapping }\end{array}$ & $\begin{array}{c}\text { Conservative } \\
\text { management }\end{array}$ \\
\hline No of infants & 59 & 53 \\
Normal & $5(9)$ & $5(9)$ \\
Neuromotor impairment, no functional loss & $7(12)$ & $7(13)$ \\
Neuromotor impairment, functional loss & $13(22)$ & $9(17)$ \\
Single non-neuromotor impairment & $2(3)$ & $1(2)$ \\
Multiple impairment & $32(54)$ & $31(58)$ \\
Overall outcome in children without a parenchymal cerebral lesion at entry & \\
No of infants & 25 & 19 \\
Normal & $4(16)$ & $3(16)$ \\
Neuromotor impairment, no functional loss & $6(24)$ & $5(26)$ \\
Neuromotor impairment, functional loss & $1(4)$ & $3(16)$ \\
Single non-neuromotor impairment & $1(4)$ & $1(5)$ \\
Multiple impairmentt & $13(52)$ & $7(37)$ \\
Overall outcome in children with a parenchymal cerebral lesion at entry & \\
No of infants & 34 & 34 \\
Normal & $1(3)$ & $2(6)$ \\
Neuromotor impairment, no functional loss & $1(3)$ & $2(6)$ \\
Neuromotor impairment, functional loss & $12(35)$ & $6(18)$ \\
Single non-neuromotor impairment & $1(3)$ & 0 \\
Multiple impairmentł & $19(56)$ & $24(71)$ \\
\hline
\end{tabular}

^For multiple impairments: relative risk $0.92,95 \%$ confidence interval (CI) 0.66 to 1.26 , percentage difference $-4 \cdot 3.95 \% \mathrm{CI}-22 \cdot 6$ to $+14 \cdot 1 ; \mathrm{p}=0.65$

+For multiple impairments: relative risk $1 \cdot 41$, CI $0 \cdot 70$ to $2 \cdot 84$, percentage difference $+15 \cdot 2$. $95 \% \mathrm{CI}-14 \cdot 1$ to $+44 \cdot 4 ; \mathrm{p}=0 \cdot 30$.

$\neq$ For multiple impairments: relative risk $0 \cdot 74,95 \%$ CI 0.55 to $1 \cdot 15$, percentage difference

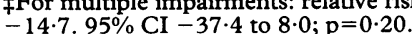

language and hearing impairment (one child), or a neurological impairment (one child).

\section{Discussion}

We were able to examine, at 30 months, 112 children with PHVD. This represents $90 \%$ of the survivors and is the largest group of such children hitherto followed into childhood. That $54(48 \%)$ scored below 70 on the overall Griffiths developmental scales and only 11 $(10 \%)$ were normal on neuromotor examination underlines the predictive value of cerebral ultrasound in this situation. The action line of $4 \mathrm{~mm}$ over the 97th centile for ventricular width $^{28}$ has proved itself consistently in differentiating (a) progressive dilatation which is likely to need treatment and has a bad prognosis from (b) transient mild dilatation after intraventricular haemorrhage that is nonprogressive and has a less serious prognosis. ${ }^{29}$ Ninety per cent of the children with parenchymal lesions noted at trial entry had neurological impairment with loss of function but $55 \%$ of children without demonstrable parenchymal lesions at entry also had neurological impairments with loss of function. This last finding may be because of the damaging effect of increased cerebrospinal fluid pressure on periventricular tissue, or the difficulties of demonstrating certain types of damage such as early stage periventricular leukomalacia using routine ultrasound. The study protocol did not require reporting of parenchymal lesions noted after trial entry so information on this is incomplete. Sixty three $(56 \%)$ children had multiple impairments, which suggests that extension of damage beyond the immediate periventricular motor area occurred. Techniques are needed to show in the neonatal period that increased cerebrospinal fluid pressure is impairing neurological function. De Vries et al have shown that somatosensory evoked potentials correlate well with increasing cerebrospinal fluid pressure and its treatment ${ }^{30}$ and this technique may have a place in the integrated assessment of infants with PHVD.

The high frequency of visual field defect $(27 \%)$ has not previously been noted and may be due to the fact that ventricles under pressure tend to expand occipitally (so affecting the optic pathways) more than frontally or laterally. Visual field defects may not have been systematically looked for in previous studies of children at this age.

With such a bad prognosis generally, improvements in treatment are desperately needed. In our follow up study at 12 months, early treatment was associated with a significant reduction in multiple impairments in children who had parenchymal lesions at trial entry. ${ }^{18}$ The borderline level of significance $(p=0.05)$ made this finding a relatively weak basis for clinical management. In addition, the children were still too young for us to be confident that all disabling non-neuromotor impairments were identified - hence our wish to re-examine the children as they grew older.

At 30 months, early tapping was not associated with a statistically significant reduction 


\begin{tabular}{|c|c|c|c|c|c|c|c|c|}
\hline \multirow[b]{3}{*}{12 Months } & \multicolumn{8}{|c|}{30 Months } \\
\hline & \multirow[b]{2}{*}{ Normal } & \multicolumn{2}{|c|}{ Neuromotor impairment } & \multirow{2}{*}{$\begin{array}{l}\text { Single } \\
\text { non-neuromotor } \\
\text { impairment }\end{array}$} & \multirow[b]{2}{*}{$\begin{array}{l}\text { Multiple } \\
\text { impairment }\end{array}$} & \multirow[b]{2}{*}{ Death } & \multirow[b]{2}{*}{$\begin{array}{l}\text { Lost to } \\
\text { follow up }\end{array}$} & \multirow[b]{2}{*}{ Total } \\
\hline & & $\begin{array}{l}\text { No functional } \\
\text { loss }\end{array}$ & $\begin{array}{l}\text { With functional } \\
\text { loss }\end{array}$ & & & & & \\
\hline \multicolumn{9}{|c|}{ No parenchymal lesion at trial entry and random allocation to early tapping } \\
\hline Normal & 3 & 3 & & & 1 & & & 7 \\
\hline Neuromotor impairment without disability & 1 & 3 & & & 1 & & 1 & 6 \\
\hline Single non-neuromotor impairment & & & & & & & & 0 \\
\hline Multiple impairment & & & & & 9 & & 1 & 10 \\
\hline Death & & & & & & 5 & & 5 \\
\hline Lost to follow up & & & & & & & 1 & 1 \\
\hline Total & 4 & 6 & 1 & 1 & 13 & 5 & 3 & 33 \\
\hline \multicolumn{9}{|c|}{ No parenchymal lesion at trial entry and random allocation to conservative management } \\
\hline Normal & 3 & 4 & 2 & & & & & 9 \\
\hline Neuromotor impairment without disability & & 1 & & & 1 & & & 2 \\
\hline $\begin{array}{l}\text { Neuromotor impairment with moderate or } \\
\text { severe disability }\end{array}$ & & & 1 & 1 & 2 & & 1 & 5 \\
\hline Single non-neuromotor impairment & & & & & & & & 0 \\
\hline Death & & & & & & 3 & & 3 \\
\hline Lost to follow up & & & & & & & & 0 \\
\hline Total & 3 & 5 & 3 & 1 & 7 & 3 & 1 & 23 \\
\hline \multicolumn{9}{|c|}{ Parenchymal lesion at trial entry and random allocation to early tapping } \\
\hline Normal & & 1 & & & 1 & & & 2 \\
\hline $\begin{array}{l}\text { Neuromotor impairment without disability } \\
\text { Neuromotor impairment with moderate or }\end{array}$ & 1 & & 1 & & 1 & & & 3 \\
\hline severe disability & & & 11 & 1 & 4 & & & 16 \\
\hline Single non-neuromotor impairment & & & & & & & & \\
\hline Multiple impairment & & & & & 13 & 1 & 1 & 15 \\
\hline Death & & & & & & 8 & & 8 \\
\hline Lost to follow up & & & & & & & 2 & 2 \\
\hline Total & 1 & 1 & 12 & 1 & 19 & 9 & 3 & 46 \\
\hline \multicolumn{9}{|c|}{ Parenchymal lesion at trial entry and random allocation to conservative management } \\
\hline Normal & & & & & & & & 0 \\
\hline Neuromotor impairment without disability & 2 & 2 & & & & & & 4 \\
\hline $\begin{array}{l}\text { Neuromotor impairment with moderate or } \\
\text { severe disability }\end{array}$ & & & 4 & & 3 & & 1 & 8 \\
\hline Single non-neuromotor impairment & & & & & & & & 0 \\
\hline Multiple impairment & & & 2 & & 21 & 1 & 2 & 26 \\
\hline Death & & & & & & 14 & & 14 \\
\hline Lost to follow up & & & & & & & 3 & 3 \\
\hline
\end{tabular}

in multiple impairments, whether or not the children had been identified as having parenchymal lesions at trial entry. One third of the children assessed at the two points in time had changed their status between 12 and 30 months, however. In addition, two children had died and seven were lost to follow up in the intervening period. Sensitivity analysis was carried out based on the most pessimistic assumption for conservative treatment (that all these losses would have had multiple impairments) and the most optimistic assumption for early tapping (that none of these losses would have had multiple impairments). This analysis showed that there was still no statistically significant difference in the frequency of multiple impairment between the two randomly allocated groups, in either those with or without parenchymal lesions at trial entry. It seems reasonable to conclude that the observation at 12 months of a reduction in multiple impairments associated with early tapping in children who had parenchymal lesions at trial entry was due to chance or the limitations of neurodevelopmental examination in young children.

We found no reliable evidence that early cerebrospinal fluid tapping improves outcome at 30 months. None of the many neurodevelopmental indices examined showed a statistically significant difference between the two treatment groups. The confidence intervals for the differences are still wide, however, and the results are still compatible with either a large benefit of the early tapping policy or even with harm. Repeated ventricular or spinal tapping was associated with a $7 \%$ risk of cerebrospinal fluid infection ${ }^{18}$ and because of this and the lack of evidence of neurodevelopmental benefit, early intervention of this kind cannot be recommended.

The risk of infection would be circumvented by drug treatment. Acetazolamide and frusemide appear to be the most promising in this respect. The combination of these treatments is being evaluated in a new multicentre randomised controlled trial. ${ }^{31}$

\section{Ventriculomegaly Trial Group}

Dr A Whitelaw (Hammersmith Hospital, London) clinical coordinator, Dr L Mutch (National Perinatal Epidemiology Unit, Oxford) neurodevelopmental follow up, Dr A Stewart (University College London School of Medicine) neurodevelopmental adviser, Dr D Elbourne, Mrs J Fooks, Dr A Grant, Mrs S Hunt, and Dr A Johnson (National Perinatal Epidemiology Unit, Oxford) central coordination and Epidemiology Unit, Oxford) central coordination and Dr J Rennie, Dr M Weindling (Liverpool Maternity Hospital),
Dr A Whitelaw (Hammersmith Hospital, London), Dr P Hope, Dr A Whitelaw (Hammersmith Hospital, London), Dr P Hope, Dr P Hamilton, Professor O Reynolds (University College Hospital, London), Dr A Wilkinson, Dr M Rochefort (John
Radcliffe Hospital, Oxford), Dr G Gandy, Dr C Morley (Rosie Maternity Hospital, Cambridge), Dr E Hey, Professor J Parkin (Princess Mary Maternity Hospital, Newcastle upon Tyne), Dr D Harvey (Queen Charlotte's and Chelsea Hospital, London), Dr D Milligan (Newcastle General Hospital), Dr R Pearse, Dr M Smith, Dr J Bridson (Jessop Hospital for Women, Sheffield), Dr E Griffin (Coombe Lying-in Hospital, Dublin), Professor G Duc (Kinderspital, Zürich), Dr T Lissauer, Dr R Rivers (St Duc (Kinderspital, Zürich), Dr T Lissauer, Dr R Rivers (St Mary's Hospital, London), Dr M Drayton, Dr P Fleming, Dr B Dr W Gorman, Dr N O'Brien (National Maternity Hospital, Dublin).

This work was supported by the National Fund for Research This work was supported by the National Fund for Research
into Crippling Diseases (Action Research for the Crippled Child) with a grant linked contribution from the National Westminster Bank. The National Perinatal Epidemiology Unit is supported by a grant from the Department of Health. We thank the families who participated in this study, and Miss B Hafner, Miss A Waterfield, Mrs E Thompson, Mrs V Boag, Dr $S$ Richards, Professor R Peto, and Dr R Collins at the Clinical Trial Service Unit. 
1 Fernell E, Hagberg G, Hagberg B. Infantile hydrocephalus: the impact of enhanced preterm survival. Acta Paediatr

2 Shankaran S, Koepke T, Woldt E, et al. Outcome after posthaemorrhagic ventriculomegaly in comparison with mild haemorrhage without ventriculomegaly. $\mathcal{f}$ Pediatr 1989; 114: 109-14.

3 Larroche JC. Posthaemorrhage hydrocephalus in infancy. Biologia Neonatorum 1972; 20: 287-99.

4 Kaiser A, Whitelaw A. Cerebrospinal fluid pressure during posthaemorrhagic ventricular dilatation in newborn infants. Arch Dis Child 1985; 60: 920-4.

5 Weller R, Wisniewski $H$. Histological and ultrastructural changes with experimental hydrocephalus in adult rabbits.

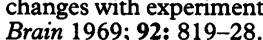

6 Weller R, Wisniewski H, Shulman K, Terry R. Experimental hydrocephalus in young dogs: histological and ultrastructural study of the brain tissue damage. Neuropathology and Experimental Neurology 1971; 30: 613-27.

7 Weller R, Shulman K. Infantile hydrocephalus: clinical, histological and ultrastructural study of brain damage. f Neurosurg 1972; 36: 255-65.

8 Hislop J, Dubowitz LMS, Kaiser, A, Singh MP, Whitelaw A. Outcome of infants shunted for posthaemorrhagic ventricular dilatation. Dev Med Child Neurol 1988; 30: 451-6.

9 Cowan F, Whitelaw A. The acute effects of acetazolamide on cerebral blood flow velocity and $\mathrm{pCO}_{2}$ in the newborn on cerebral blood flow velocity and $\mathrm{pCO}_{2}$ in

10 Keisu M, Wilholm BE, Ost A, Mortimer O. Acetazolamideassociated aplastic anaemia. F Intern Med 1990; 228: 627-32

11 Papile L-A, Burstein J, Burstein R, Koffler H, Koops BL, Johnson JD. Post-haemorrhagic hydrocephalus in lowbirthweight infants: treatment by serial lumbar punctures. f Pediatr 1980; 97: 273-7.

12 Lipscomb A, Thorburn R, Stewart A, Reynolds E, Hope P. Early treatment for rapidly progressive posthaemorrhagic hydrocephalus. Lancet 1983; i: 1438-9.

13 Kreusser KL, Tarby TJ, Kovnar E, Taylor DA, Hill A, Volpe JJ. Serial lumbar punctures for at least temporary amelioration of neonatal posthaemorrhagic hydroamelioration of neonatal posthaem

14 Cooke RWI. Determinants of major handicap in posthaemorrhagic hydrocephalus. Arch Dis Child 1987; 62: 504-17.

15 Mantovani JF, Pasternak JF, Mathew OP, et al. Failure of daily lumbar punctures to prevent the development of hydrocephalus following intraventricular haemorrhage. f Pediatr 1980; 97: 278-81.
16 Anwar M, Kadam S, Hiatt IM, Hegyi T. Serial lumbar punctures in prevention of posthaemorrhagic hydrocephalus in preterm infants. $\mathcal{f}$ Pediatr 1985; 107 446-9.

17 Dykes RD, Dunbar B, Lazarra A, Ahmann P. Post haemorrhagic hydrocephalus in high-risk preterm infants: natural history, management and long-term outcome. $f$ Pediat 1989; 114: 611-8.

18 Ventriculomegaly Trial Group. Randomised trial of early tapping in neonatal posthaemorrhagic ventricular dilatation. Arch Dis Child 1990; 65: 3-10.

19 Levene MI. Measurement of the growth of the lateral ventricle in preterm infants with real-time ultrasound. ventricle in preterm infants with
Arch Dis Child 1981; 56: 900-4.

20 Gairdner D, Pearson J. A growth chart for premature and other infants. Arch Dis Child 1971; 46: 783-7.

21 Amiel-Tison C, Stewart AL. Follow up studies during the first 5 years of life: a pervasive assessment of neurological function. Arch Dis Child 1989; 64: 496-502.

22 Griffiths R. The abilities of young children. Amersham: Association for Child Development, 1954.

23 Reynell J, Huntley M. Reynell developmental language scales. 2nd Ed. Windsor: NFER Nelson, 1985.

24 Sparrow S, Balla DA, Cichetti DV. Vineland adaptive behavioural scales. Minnesota: American Guidance Service Inc, 1984.

25 Watt $\mathrm{H}, \mathrm{Bax} \mathrm{M}$, Whitmore M. Child psychology services in the inner city infants school. London: Thomas Coram Research Unit, 1980 .

26 Tanner JM, Whitehouse RH, Takaishi M. Standards from birth to maturity for height, weight, height velocity and weight velocity: British children, 1965. Part I. Arch Dis Child 1966; 41: 454-71.

27 Sonksen PM. The assessment of 'vision for development' in severely visually handicapped babies. Acta Ophthalmol Suppl (Copenh) 1982; 157: 82-90.

28 De Vries LS, Larroche JC, Levene MI. Intracrania sequelae. In: Levene MI, Bennett MJ, Punt J. Fetal and neonatal neurology and neurosurgery. Edinburgh: Churchill neonatal neurology and neur

29 Costello AM de L, Hamilton PA, Baudin J, et al. Prediction of neurological impairments at four years from brain ultrasound appearance of very preterm infants. Dev Med Child Neurol 1988; 30: 711-22.

30 De Vries LS, Pierrat V, Minami T, Smet M, Casaer P. Th role of short latency somatosensory evoked responses in infants with rapidly progressive ventricular dilatation. Neuropediatrics 1990; 21: 136-9.

31 British Association of Perinatal Medicine: Perinatal Clinical Trials Group. Newsletter No 2. Oxford: NPEU, 1993. 